\title{
Developing Emergency Response Shelter in Place Guidelines for Pilgrim upon Natural Hazard Occurrence in the Sacred Sites in Makah
}

\author{
ABDULRAHMAN M. BASHAWRI \\ Urban \& Engineering Researches Department, THE CUSTODIAN OF THE TWO HOLY MOSQUES INSTITUTE FOR \\ HAJJ AND UMRAH RESEARCH, UMM AL-QURA UNIVERSITY, MAKKAH, SAUDI ARABIA. \\ E-mail: ambashawri@uqu.edu.sa
}

\begin{abstract}
Maintaining up-to-date guidelines for an emergency shelter response (ESR) is crucial for serving Rahman guests when natural hazards, such as floods, storms and rockslides, occur, particularly during large-scale holy events, such as Hajj. ESR guidelines are vital for ensuring that cleaner, greener and more secure and private places for survival are provided to those who been affected so they may complete their worship. A qualitative research design was employed for this study in order to analyse case studies, existing guidelines and the literature in relation to the development of an appropriate ESR. The analysis indicated that existing guidelines are relatively ineffective. The guidelines available in Saudi Arabia provided some knowledge and information but little help on developing ESR guidelines for natural hazards in sacred sites (including Mina, Muzdalifah and Arafat) in Makkah, where focused and quick guidance is desired, as stated by the General Directorate of Civil Defence.To achieve the objective of Saudi Vision 2030 to develop and improve services provided to Rahman guests, this study recommends improved guidelines involving multiple stages for the development of an ESR to guarantee that the performance and provision of the ESR are effective. The proposed guidelines will help stakeholders to manage decision-making, whilst giving them the required information to account for the environmental, sociocultural, economic and technical elements that must be considered in the implementation of response processes in order to maximise the fitness of the response for achieving its purpose and to save the lives and protect the welfare of the Rahman guests so they may continue their worship.
\end{abstract}

Keywords: Emergency Shelter Response Guidance, Natural Hazards, Sacred Sites, Design Factors, Decision Makers

JEL Classification: Z0, Z130

Recibido: 9 de Febrero de 2021

Aceptado: 16 de Marzo de 2021 


\section{Introduction}

Much interest has been shown recently in establishing and maintaining guidelines for an emergency shelter response (ESR) for evacuees after natural hazards, such as floods, storms and rockslides. Worldwide, thousands of people must desert their homes because of natural hazards each year [1]. Emergency shelter must be provided as part of hazard recovery efforts; however, it is unclear what type of shelters are most relevant for different circumstances and emergencies [2, 3]. Many environmental, sociocultural, technical and economic issues can affect survivors when emergency shelters are incorrectly planned $[2,6]$. Existing ESR documents and emergency shelter guidelines in Saudi Arabia were reviewed and found to be generic in nature and lacking the necessary elements to enable those responsible to deliver the essential ESR to those affected by natural hazards in Hajj event (59 and 61). Without the appropriate response guidelines, decisions can be rushed and services improvised, which can further disrupt the lives of survivors and site workers and also negatively affect organisations $[5,6]$.

Thus, it is necessary to improve ESR policies and procedures. In response, a qualitative approach was used as part of this research to develop recommendations for appropriate ESR guidelines in sacred sites in Makkah. The steps followed to develop an effective ESR included holding committee meetings, conducting a design factor analysis, considering options for shelter types, identifying ambitions and needs, examining implementation, assessment and monitoring procedure and reflecting on the outcomes. This process should be followed to identify the needs of Rahman guests, to perform assessments and to establish a plan for the provision of an effective ESR. The intention of this study was to recommend ESR guidelines based on research to maximise their appropriateness for serving Rahman guests, saving their lives and protecting their welfare in an efficient and cost-effective manner so the guests can continue their worship. The intention was not to recommend a highly detailed design for emergency shelter procedures but rather to focus on design factors that reflect the local sociocultural, technical, economic and environmental context and contribute to the an ESR founded on easier, more expedient and better-informed decision-making processes.

\section{Emergency Shelter}

Ensuring that appropriate and adequate emergency shelter is available when needed is an ongoing procedure that must be routinely assessed and updated as needed [2 and 7]. An emergency shelter is a habitable, covered living area that is provided as part of emergency aid efforts. The provision of emergency shelter must be supplemented with the provision of blankets, clothing, mattresses and services, such as sanitation and water. It has been suggested that emergency shelter areas should be green, sanitary, private, safe and humane for those who have been displaced so they have appropriate shelter until they are able to return to their normal routines [8]. Typical examples of emergency shelters in sacred sites in Makkah includes the Ma'aisam accommodation camp, with a capacity of 10 thousand pilgrims, the two camps in Arafah with a capacity of more than 10 thousand pilgrims each, the shelter camp in Muzdalifah, which accommodates about 30 thousand pilgrims, in addition to schools, sports facilities and wedding palaces near the Holy places.

\section{Natural Hazards}

There is a strong need for a line of rapid response to guide appropriate actions when faced with natural hazards. Some calamities, such as famines, droughts and civil conflicts, are preceded by warning signs and, therefore, do not usually require a rapid response [13]. However, research has shown that unexpected natural hazards occur quickly and with the immediate result of lost lives. Benthall [32] stated that natural hazards are not necessarily instigated by human activity. However, they must be mitigated by the efforts of humans. These efforts are facilitated by thorough preparedness on the part of both private citizens and public authorities. Sacred sites including Mina, Muzdalifah and Arafat as shown in Figure 1. The hazards in the holy places including infection (such as 
Covid - 19), stampede, crowding, firing, flooding and heat stroke. The most risky area which caused flooding are Mahsar Valley and Arnah Valley as shown in figure 2.

Figure 1: Holy places in Makkah

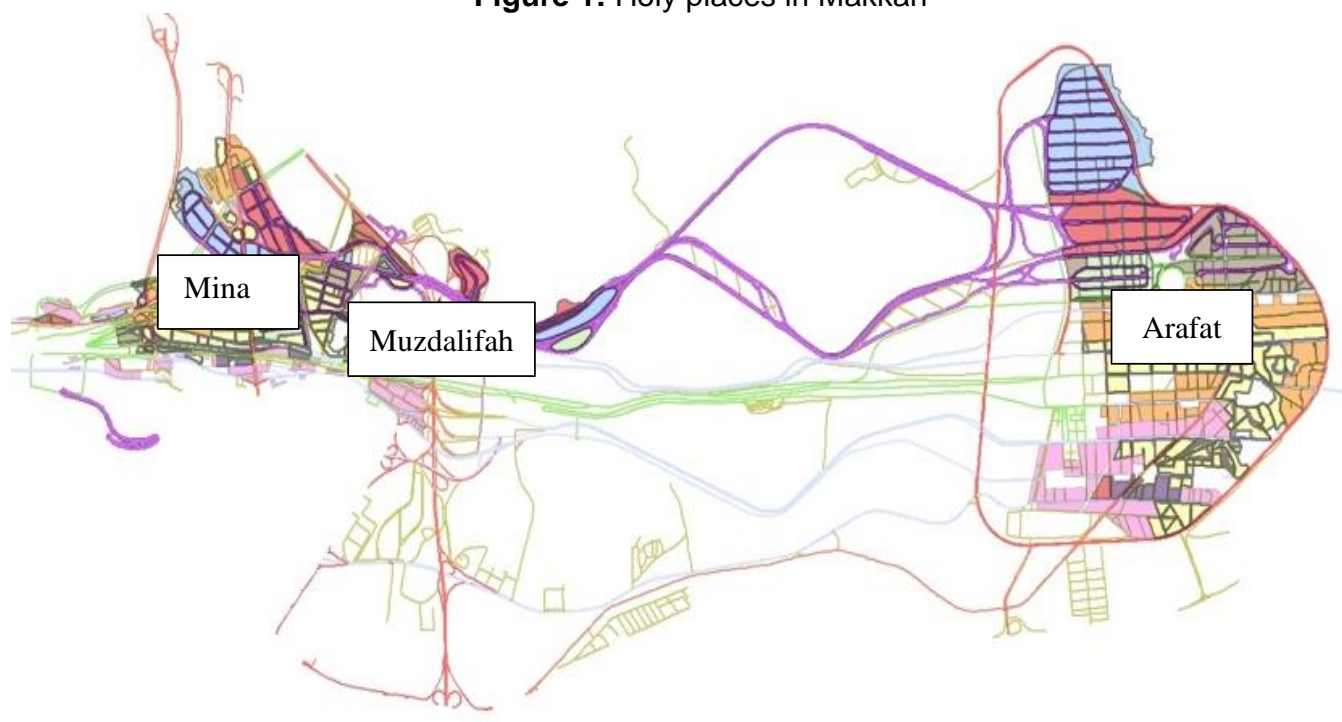

Figure 2: Mahsar Valley and Arnah Valley in holy places

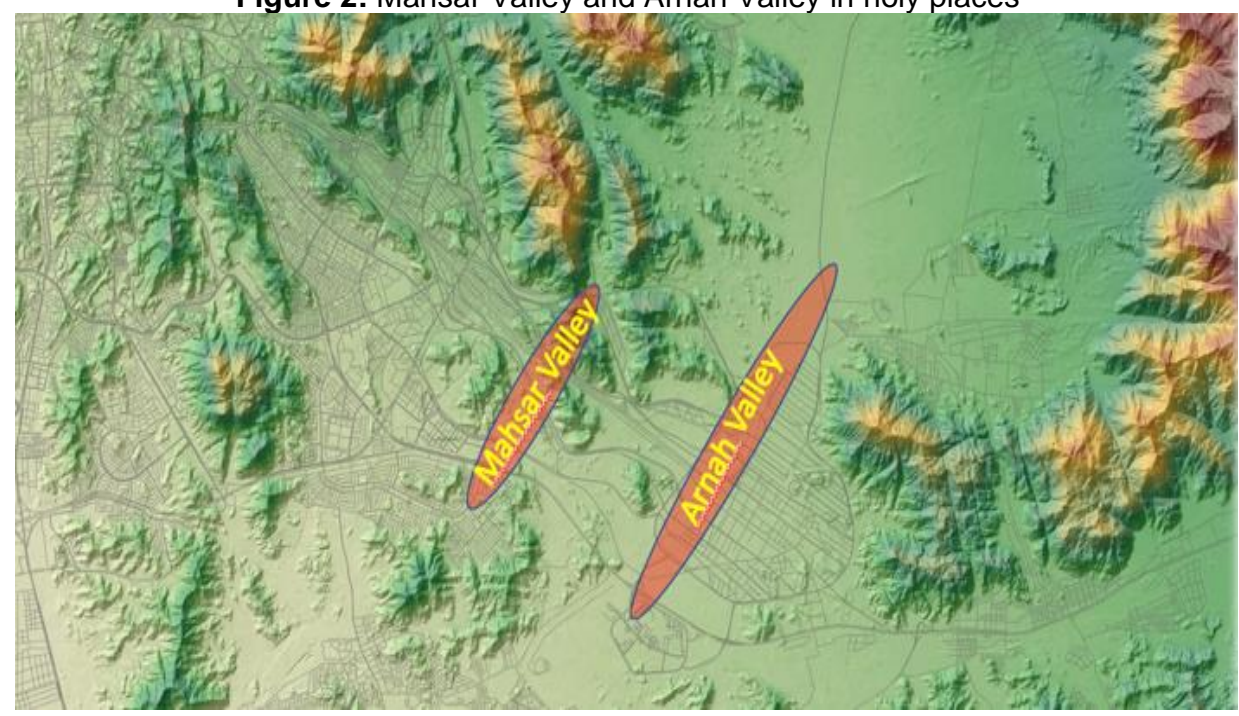

One of the most severe hazards that occurred during a holy event in Saudi Arabia, which took place during the Hajj period and received considerable global media coverage, was the crowding tragedy in 2015, an event described as a 'crush and stampede'. The rush of pilgrims in Mina on the morning of 24 September, specifically, at nine in the morning, resulted in the death of 717 pilgrims, while 863 others were injured. The Civil Defence reported through its Twitter account that it had established two medical screening areas and explained that the stampede occurred at the entrance to Jamarat, at the intersection of Streets 204 and 223. The second hazard of note was flash flooding. In 2019, heavy showers fell on Mina. Immediately, the pilgrims began taking precautionary measures, in accordance with the instructions of Saudi Civil Defence officials, to separate electricity from the camps and raise the wooden ceilings to prevent them from falling on the pilgrims.

It is vital for the government to develop effective ESR guidelines to ensure the provision of necessary services for Rahman guests following incidents such as these. Moreover, previous experiences with such situations support the need for ESR guidelines appropriate for various circumstances that can be used in practice. Therefore, this paper provides recommendations for guidelines that include the planning and implementation stages necessary to make the ESR appropriate, successful, quick and easy. 


\section{Research Methodology}

This research was conducted using a qualitative approach. The qualitative approach frequently includes an in-depth literature review and interviews [38]. The in-depth literature review technique aims to identify existing materials and information regarding the theme of the study [34]. During the review, information related to the study problem and research question is collected. This enables the investigator to uncover the necessary background details, theories, findings and gaps in the literature related to the topic of study to inform relevant study results [35 and 36]. For this, it is important for the investigator to obtain the most relevant and current information from the literature, to have thorough technical know-how, to review information related to the topic under review and to have access to the necessary resources, including time [37 and 38].

For the current study it was necessary to review the literature and other available documentation to discover subjects related to ESRs and any linked matters that have appeared in publications. Thus, the in-depth literature review technique was performed to critically examine the associated literature and documentation. Firstly, existing available guidelines, both from Saudi Arabia and international sources, were evaluated in detail with an emphasis on the ESR for natural hazards in the context of holy places and the particular issues that relate specifically to such contexts. Then, examples of existing provisions of emergency shelters following natural hazard situations were gathered. Furthermore, a variety of factors that need to be considered in order to improve the performance of Saudi's ESR following a natural hazard event in holy places were identified.

The data gathered was processed through the stages of data analysis proposed by Tesch [49]. These stages comprised establishing the underlying meaning of the problem, collecting a list of all steps in ESR planning identified through the research, categorising these steps, coding the steps and evaluating their complexity with the aim of articulating inter-relationships and then classifying them under firm headings and, finally, creating a fixed choice on the coding of the headings. After that, guidelines for developing an effective ESR for a natural hazard situation in sacred sites were built and structured.

The interview technique is also used in qualitative research, as it is a valuable method for information gathering [54]. This technique allows the researcher to gain rich, real life and in-depth data from participants. In the qualitative methodology, participants are selected based on the following four factors: the actions of the participants in the ESR, the study setting, the participants themselves and the procedure through which the actions of the actors develop within the setting [54]. The main reason for conducting interviews in the current study was to gather input from individuals qualified to assist the investigator in validating best practices to include in the ESR guidelines; thus, members were selected in a manner that best achieved that goal. A structured outline of interview questions elicited qualitative comments through open-ended questions, which were included with quantitative closed-ended questions applying the Likert scale to minimise the labour involved and to guarantee that all components were measured similarly. The in-depth review of the literature and the interview technique for validation of the data gathered during the review are explained in more detail in the following sub-sections.

\subsection{Review of Existing ESR Guidelines}

The literature review began with an examination of the two existing plans related to ESRs in Saudi Arabia that were available: (1) Executive Plan for the Tasks of Hajj and Umrah and the Affiliated Parties

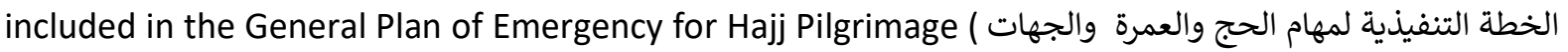

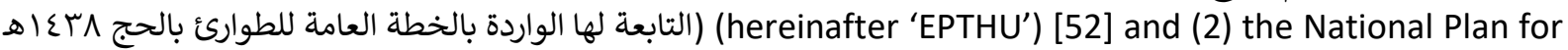
Natural Disaster Risk Reduction (الخطة الوطنية لمواجهة مخاطر الكوارث الطبيعية (hereinafter 'NPNDRR') [51]. These documents were found online on the website of the General Directorate of Civil Defence. A critical review of the two documents revealed that the EPTHU is more focused on the natural and nonnatural hazard responses for Hajj. It offers a plan for an evaluation and sheltering process, which includes the following: evacuating the affected parties from the outdoor camps and buildings and transferring them to a safe area; providing translators to interpret the emergency procedures, if 
required; arranging the necessary spaces to shelter affected people; applying the necessary human resources (e.g. internal pilgrims and pilgrim organisations) for the evacuation and shelter processes; and a procedure for approximating the number of people affected who were vacated and classifying them according to their nationalities to the degree possible. Although the EPTHU does not provide detailed information for ESR procedures following different types of emergencies, such information needs to be considered when developing ESR guidelines.

The NPNDRR provides information on different types of shelters, including permanent buildings, both public and private, and large spaces to accommodate tents. However, the document is lacking in the following areas: documentation of a procedure for distributing the tents; criteria and factors decision-makers must consider to facilitate the expedient and effective provision of emergency shelter; the appropriate authorities who should participate in the ESR and their roles in related processes; and a plan for reviewing and making necessary improvements to related procedures and services. Importantly, the document does reference the need to regularly review and revise the ESR guidelines.

Also identified during the literature review were international resources that provided guidelines and methods for ESR planning, including shelter responses used in emergency events, from which useful information was gleaned on the following procedures: distributing shelter-in-place plastic sheeting [41], distributing shelter kits [22], determining whether and how to distribute tents [42] and implementing a transitional shelter programme [543], as well as a framework for a strategic programme of temporary housing [5]. The literature review was completed by identifying best practices for response methods, the order of the steps involved, the main criteria suggested for ESR guidelines and the steps and limitations of each response process reviewed.

One relevant procedure reviewed was for the distribution of shelter-in-place plastic sheeting [41]. Factors mentioned that need to be evaluated before building new constructions using plastic sheeting were maintenance, need assessments and siting. Other factors to consider include the climate, materials needed, product lifetime, stages of response, lead time, gender-related issues, associated costs, adaptations, cash distribution and coordination. After assessing those factors, the plastic sheeting use, size and fixing tools for use must be considered, as well as providers of the product. Moreover, a flowchart was used to move from step to step to facilitate easier decision-making.

Another procedure evaluated was the distribution of shelter kits [22]. It is recognised that before supplying the shelter kits, a planning committee should conduct an assessment to help those responsible to arrive at a clear decision for providing the shelter kits, including a materials assessment, needs assessment, capacity assessment and vulnerability/skill assessment. After performing these assessments, the distribution begins, and the process is evaluated and monitored. A flowchart was also used for this process to guide the set-up procedure and identify the issues that require attention at each stage of the process.

Making the determination to distribute tents was another procedure reviewed [42]. As with the other procedures described thus far, a flowchart outlined the progression from step to step. Useful information on steps to follow and criteria to assess were gathered for this process from the literature. These steps and criteria can be developed within the ESR guidelines. One issue that was mentioned that should be included in the guidelines is consideration of other sheltering options available, such as permanent buildings (halls, schools and so on), before deciding to distribute tents. Considering this step can minimise the impact on the environment related to the temporary shelter structure or camp and decrease both economic and social costs. Moreover, the method reviewed also noted other factors to consider, namely, cultural matters, vulnerable people, the nature of the host population, weather/climate and shelter requests that vary according to time period, public participation and politics.

The next method reviewed related to establishing a transitional shelter programme [43]. The literature on this process mentioned that it is important to include the affected people in the decisionmaking process to allow them to select the method for their recovery response most suitable for them 
from the beginning emergency stage until returning to normal routines. This approach is split into four divisions: appropriateness, internal capacities, shelter properties and assistance methods. The first section considers the associated factors and criteria that help decision-makers select a suitable form of shelter response. The factors are community, assessment, strategy, standards, vulnerability, maximising choices, incremental processes, buying time, site planning and reconstruction. Moreover, other issues to consider that can be useful in the immediate response include capacities, shelter site, design features, risks, climate, materials and labour approaches. Once again, a flowchart approach was used to expedite the decision-making process.

The final element of ESR planning reviewed in the international literature was development of a framework for a strategic programme of temporary housing [5]. The first stage in developing a strategic plan is to consider factors such as organisational design, vulnerable populations, local conditions, overall reconstruction, design and materials, locations, services, long-term uses and outcomes. After these factors are considered, this process can be left on hold until such time when a hazard takes place. At that point, the strategic plan needs to be updated to the level of tactical needs to coordinate it with the conditions of the specific hazard. In addition, the same factors need to be considered again, if the 'wait for next hazard' situation prevails. However, the research argued that after the evaluation, time is limited for gathering the necessary information, and the quality of the decision process might subsequently be prejudiced, as a significant amount of time is needed to adequately consider each factor. The literature was not clear on the details that need to be collected and addressed, but it would be optimal to identify them in advance before the hazard occurs.

The guidelines available in Saudi Arabia provided some knowledge and information but little help on developing ESR guidelines for natural hazards in holy sites, where focused and quick guidance is desired, as stated by the General Directorate of Civil Defence [51]. Furthermore, criteria or factors to consider for the development, assessment and implementation of the response are not mentioned, nor are the steps that need to be followed to implement the ESR process quickly and easily. Only general information is contained in these documents regarding the need to shelter affected people in safe places and provide them with required supplies and services (without identifying those requirements with any specificity).

In addition, none of the available global approaches was sufficiently helpful in providing guidance for the planning stages, as the materials primarily targeted those responsible for making decisions and those who are involved at natural hazard sites and who deliver ESRs quickly and simply to those in need in holy places in Saudi Arabia. Each type of natural hazard has its own specific context that arises only when the natural hazard has struck. Still, there are some features within identified best practices that may inform ESR guidelines for improving ESR approaches for a natural hazard event in the Hajj context. Therefore, it is strongly suggested that plans reflect the significant criteria and phases establishes in ESR guidelines for an appropriate, rapid, easy and successful ESR that engages all responsible stakeholders in Saudi Arabia in delivering the ESR during and following hazard situations.

Many of the procedures described in the literature incorporate a flowchart approach, which involves an outline of a series of steps to be followed [58]. Each step can be iterative, and the chart routinely focuses on one stage in a process, which makes it easier for decision-makers to return to prior steps to develop additional outcomes, if needed. This approach has many benefits, like reducing the risk of having to generate expensive changes late in a procedure and establishing a formal plan for implementation of a procedure. Each step generates a certain result that can be assessed before executing subsequent steps. Within each stage, different groups of decision-makers can work in parallel. Since the flowchart approach is used in all methods of shelter response, the researcher considers that this approach is appropriate for improving the ESR for a natural hazard in the Hajj context, where quick and immediate results are needed.

The factors and steps that should be included in the ESR guidelines may differ for different countries and in response to different hazards. This important detail influenced the query into which ESR guideline protocol provided the most successful procedures for the current context. Nevertheless, basic emergency shelter needs will be similar in most emergency situations. Review of existing 
methods enabled the identification of essential elements that are applicable and indispensable to the ESR for natural hazard situations in holy places, which include the following: materials, needs, vulnerability/skills, maintenance, capacity, location, type of shelter, product lifetime, climate, time, gender, cost, adaptation, coordination, cash distribution, use, providers, fixing tools to repair and build, size, cultural issues, maximising choice, community, design characteristics, incremental process, risks, labour, equality, basic services, environmental friendliness, protection, displacement and sensitive communication.

After analysing the stages, as recommended by Tesch [49], the next important step for all ESR guidelines is identifying the key responsible people to be engaged in a committee in order to analyse and discuss the main criteria and factors that make the ESR successful [22, $51 \& 52]$. This committee is also integral to the implementation of subsequent stages, such as considering sheltering types [42 \& 43], needs and ambitions [ $22 \& 41]$, assessment [ $22 \& 53$ ], implementation [ 43 \& 5], monitoring [22 $\&$ 5], and lessons learned [ $22 \& 43]$. All identified factors and stages were validated by experts with the appropriate education and prior experience in responding to hazard situations, as explained in the next sub-section.

\subsection{Validation of ESR Guidelines}

After the essential elements for ESR guidelines were identified through the in-depth review of the literature and existing guidelines, a validation procedure needed to be implemented by applying the Likert scale to minimise the labour involved and to guarantee that all components were measured similarly.

The validity of the process-based ESR guidelines may be assessed without the obligation of resources or the need to meet any requisite timelines or impose any organisational burdens. It may require extended time to gather input. Consequently, it is not always possible to use certain methods for validation. For this research, the validation of the guidelines was performed by a collection of professionals with varying areas of expertise through the interview process. This method increased the possibilities for gathering valued insights into the subject under investigation.

Bryman and Bell [53] claimed that in this type of research, the structured interview technique is recommended. This technique involves developing a standardised series of questions on which to base and improve the interview. This allows participants to have greater control of the answers they give in response to the questions posed during the interview. By conducting interviews, the researcher was able to encourage the interviewees to explain, elaborate on or amend their statements.

The ESR guidelines were tested by several specialists who have important knowledge in the field of natural hazards in sacred sites in Makkah, including the following: the General Directorate of Civil Defence (a director of risk analyses division - years' experience 10), the General Administration of Civil Defence in the Holy Capital ( a director of safety unit - years' experience 15), a Ministry of Hajj and Umrah (a counsellor - years' experience 30), a National Risk Unit (a deputy manager of the unit - years' experience 5), a Hajj and Umrah Research Institute (a professor - years' experience 30) , the Makkah Province Emirate (a head of operation in crisis and disaster Management Centre - years' experience 15), and Disaster Centre in the Holy City Secretariat and Royal Commission for the City of Mecca and the holy places (a counsellor - years' experience 20). These individuals worked as senior officials in their respective organisations and were qualified by virtue of their high levels of education and extensive experience. Furthermore, they had been involved with several natural hazards situations in sacred sites in Makkah and also conducted research work related to natural hazards.

The Excel programme was used to analyse the data gathered during the interviews. The experts were asked to rate the importance of each phase of the ESR guidelines and also to add any missing elements that they deemed important and to prioritise all elements of the guidelines. Moreover, they were also asked for their opinions on any additional factors that would add significance to the ESR guidelines. 
The extent to which the established ESR guidance's stages were valued according to their significance was assessed on a 5-point Likert scale ranging from 'very high $=5$ ' to 'very low $=1$ '. All of the experts interviewed agreed that the stages of the ESR guidelines, outlined as follows, were highly important, as indicated in Figure 3: stage 1 (S1) establish meeting committee; stage 2 (S2) analyse relevant factors; stage 3 (S3) investigate sheltering types; stage 4 (S4) identify needs and ambitions; stage 5 (S5) assess plan; stage 6 (S6) implement plan; stage 7 (S7) monitor implementation; and stage 8 (S8) reflect on lessons learned.

Figure 3: Outcomes of experts' evaluations of response stages

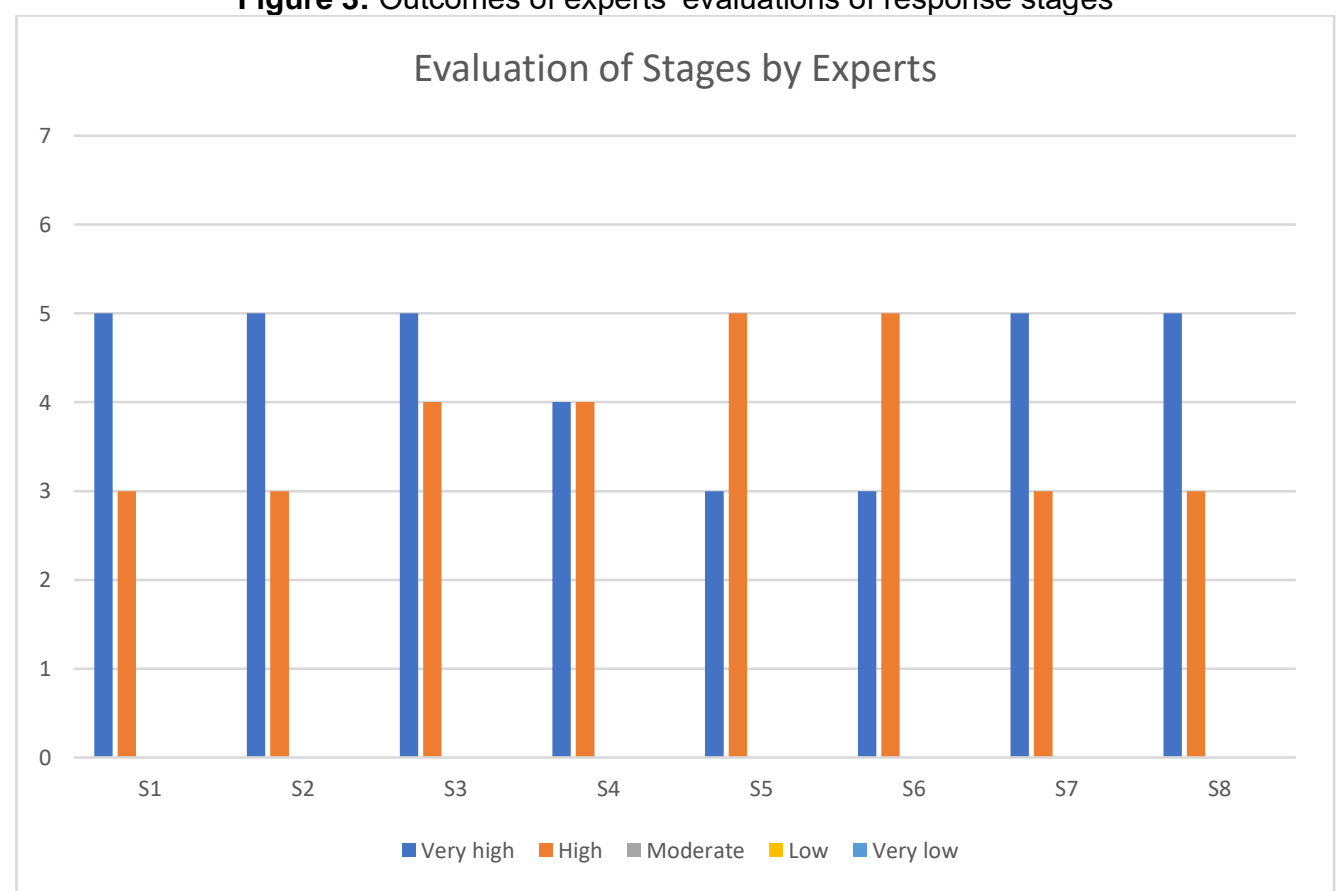

An assessment of ESR guidelines that examines it from the perspective of six attributes of effectiveness can contribute to determining its appropriateness. One attribute is efficacy, which refers to the degree to which the ESR guidelines will achieve the desired outcomes, which is to help decisionmakers to decide on a suitable ESR and to develop ESR guidelines for acting quickly and simply in order to protect life, decrease the impacts of the response and provide conditions that support a return to normal routines. Practicality refers to the level at which the ESR guidelines will inspire action, rather than theory or speculation, to accomplish the planned aim. Helping decision-makers assess to what extent the ESR guidelines will lead to the successful achievement of long-term goals is tied to the decision-makers' expectations. Moreover, the effectiveness of the ESR guidelines in guiding the development of an ESR that saves lives, money and time are additional attributes. Word Excel software was used for a descriptive statistical analysis to objectively measure the six attributes of the ESR guidelines. The assessment of the degree to which the six attributes of the ESR guidelines succeeded in meeting expected objectives indicated high degrees of success for most attributes, as illustrated in Figure 4.

Aspects of the ERS response framework such as its efficacy, its practicality, its helpfulness to decision makers, its potential to save lives, money and time were prioritised on a 5-point Likert scale namely; 'extremely $=5$ ', 'very $=4$ ', ' moderately $=3$ ', 'slightly $=2$ ' and not $=1$ '. This assessment indicated that the ESR guidelines were practical and effective and that the comprehensive procedure will successfully assist those responsible in making decisions that will save lives, money and time. The outcomes show that all six attributes are highly significant and have almost equal levels of importance. Some interviewees proposed that the ESR guidelines require testing at a real hazard event to arrive at results that can be added, such as new factors and stages to update and develop the ESR guidelines. Nevertheless, a committee should include the members (and expertise) necessary in order to create a full picture that incorporates different perspectives to work together and succeed in performing its 
duty. The last comment was that the factors involved in the second stage should be updated regularly because each hazard has its own challenges and needs.

Figure 4: Evaluation of approach attributes

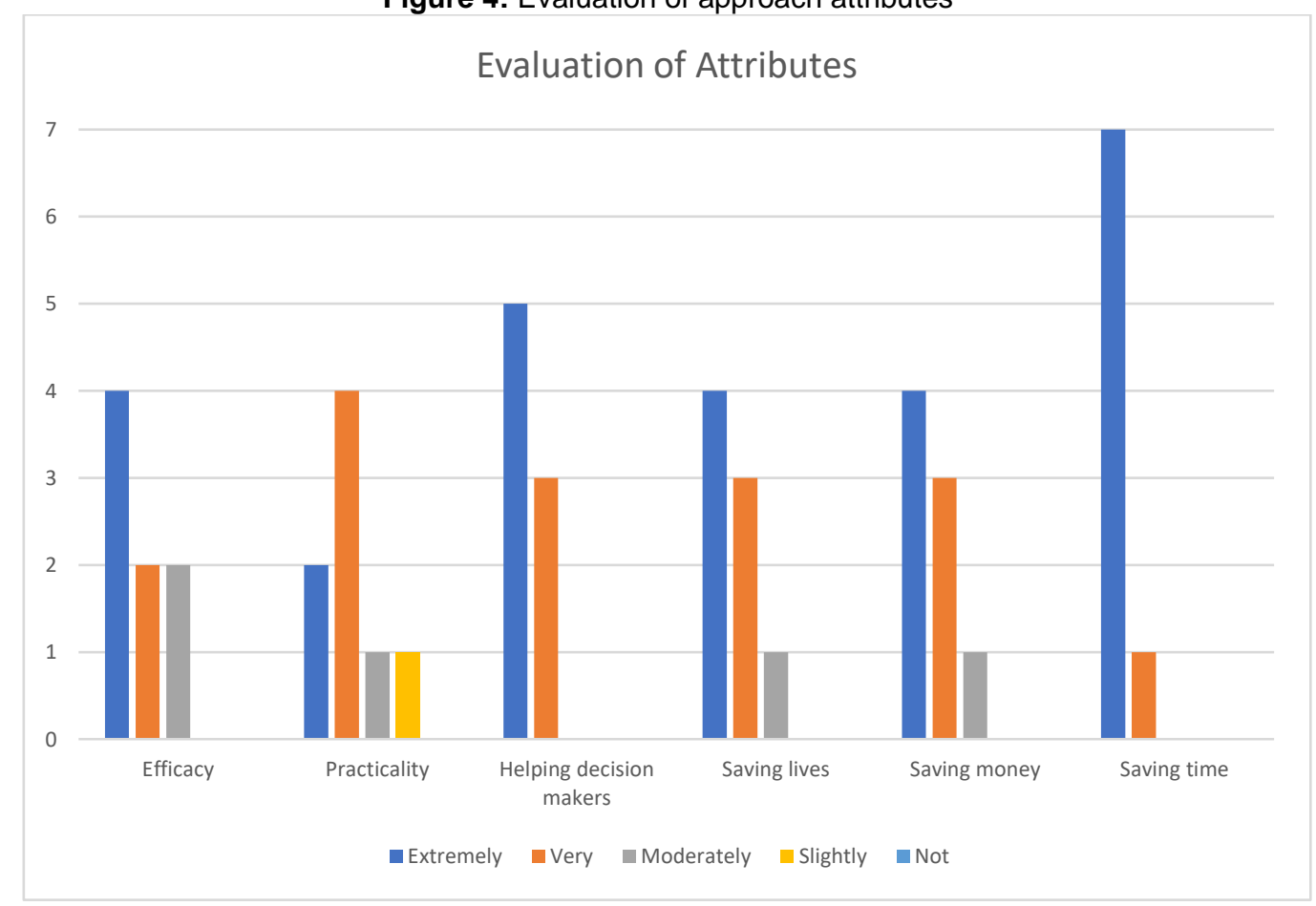

\section{Guidelines for ESR}

It is difficult to identify a single method template appropriate for an ESR that can assist decisionmakers in making the right decisions about the most satisfactory shelter response [51 and 52], especially for emergency responses within the Hajj context, even though the basic shelter response is similar for most emergencies [47]. The need to make such difficult decisions that must be made with a high level of urgency and that carry significant possible consequences places great accountability on the officials and planners involved [39]. Therefore, guidelines for an ESR for a natural hazard to serve Rahman guests that provides a safe location to protect those affected and decreases difficulties in its implementation must be created [51 and 52]. In addition, it is assumed that the guidelines will establish an effective method to assist participants in successfully achieving the goals of the ESR.

While no one template exists that can be duplicated in this context, various aspects of different methods can be used in part. Therefore, the author has developed guidelines that can support the persons responsible as they consider the most important factors during natural hazards in order to come up with a suitable response by combining various components gleaned from multiple sources appropriate for the current context. An important aspect of such guidelines is recognising that developing an appropriate approach is a continual process that requires monitoring. It must not be considered an open and closed process [47].

These guidelines comprise eight stages, illustrated in Figure 5: stage 1 (S1) establish meeting committee; stage 2 (S2) analyse relevant design factors; stage 3 (S3) investigate sheltering types; stage 4 (S4) identify needs and ambitions; stage 5 (S5) assess plan; stage 6 (S6) implement plan; stage 7 (S7) monitor implementation; and stage 8 (S8) reflect on lessons learned. As noted previously, experts agreed on the relevance and importance of these stages. An important feature of the guidelines is providing an opportunity for interaction. This helps the responsible parties to define the nature of the need so the appropriate response can be implemented quickly and easily. 
Figure 5: Guidelines for emergency shelter response (ESR)

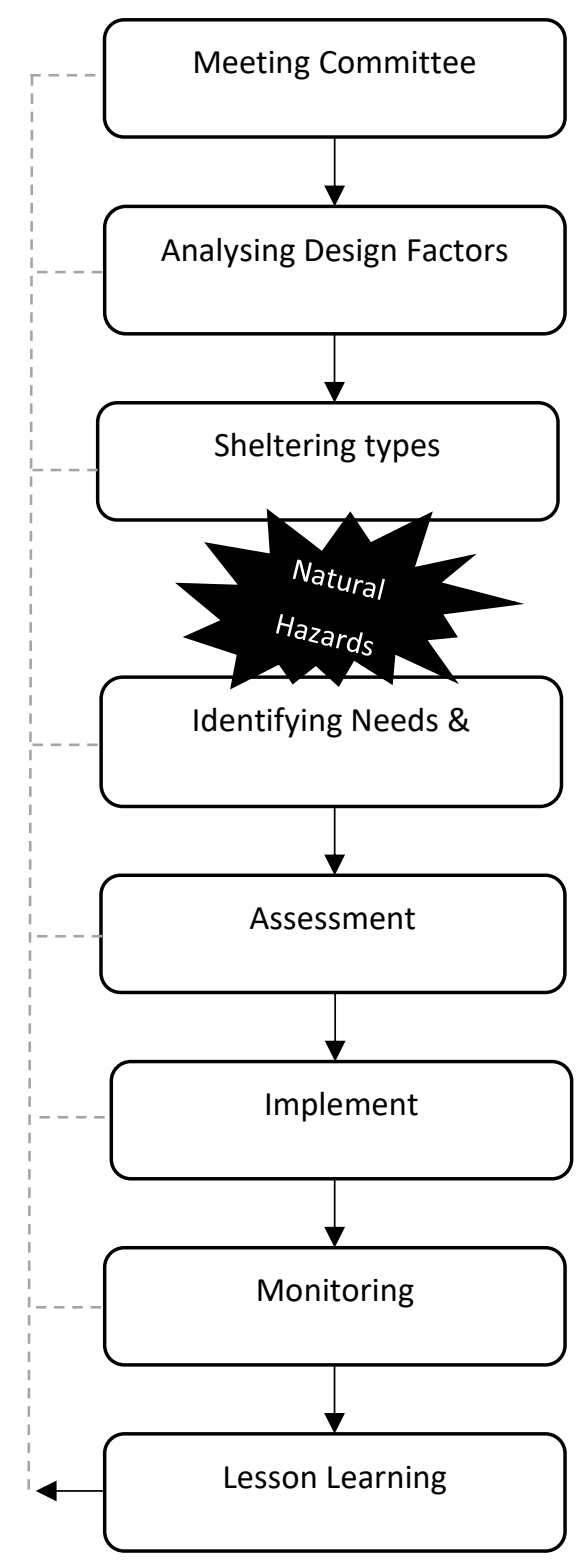

\subsubsection{Stage 1-Meeting of the Committee}

Successfully providing an ESR for Rahman guests requires coordinated multi-agency responses [22, 51 \& 52]. Coordination must be consistent between organisations and response sectors within organisations that can access resources $[16,17]$. For instance, the ESR must not be implemented without coordinating hygiene promotion activities and water sanitation as needed; therefore, there is a need for coordinating water, food, health, electricity and security services.

Many organisations need to collaborate to make sure that Rahman guests transfer from the hazard site to a secure location with the necessary protection and support until they are able to return safely to their worship site. It is vital that responses are locally managed and coordinated with local leaders present at the hazard site, as there is a need for familiarity with the circumstances of the Rahman guests. Leaders are selected based on their competencies, skills, knowledge, experience and willingness to organise and manage. Those with responsibility for facing the hazards are identified in the NPNDRR [51], which includes the appropriate officials and representatives from the following: Ministry of Defence; Ministry of the Interior; Ministry of Hajj and Umrah; Ministry of the National Guard and so on. Each individual and organisation in the committee needs to be well-defined and 
aware of their responsibilities and tasks in advance before natural hazards strike, such as what they are to do, how, when, and where.

Primary responsibility for ensuring Rahman guests are safely sheltered in hazardous situations belongs to the General Directorate of Civil Defence. This is achieved by choosing available buildings, such as hotels, halls, mosques or open areas in which to run the emergency camps and manage them by coordinating with other organisations. The General Directorate of Civil Defence also assists the Ministry of Finance in providing funds to meet nutrition needs and in ensuring that simple facilities and services, like water and electricity, are provided in the permanent location used, as well as in areas used for emergency camps. In the case where tents are provided, the Ministry of Finance must maintain a sufficient number of fire-resistant tents and store them for an emergency. This comprises acquiring the remainder of relief supplies and being prepared to increase the quantities, if required. The Ministry of Finance should have a plan to provide enough manpower to construct and load the tents. Additionally, they must be involved in the response from the start of the plan's implementation, up until the tasks are finished, and be prepared to increase the number of personnel involved, if required.

\subsubsection{Stage 2-Analysing the Design Factors}

After formation of the committee, it is crucial to debate different elements related specifically to the Hajj context, and those design factors, which include the environmental, sociocultural, economic and technical elements, need to be updated from time to time and from hazard to hazard, as described below.

1. Environmental factors include variations in the climate; upgrade, recycling and disposal of materials; hygienic air and water supplies; being environmentally friendly; water and air quality; minimising water and energy consumption; and reducing waste [30]

2. Sociocultural factors include language and cultural differences, if any; maintaining inhabitants' security and dignity; psychological and physical effects of hazards; ensuring equality; communication; and support for vulnerable persons.

3. Economic factors include budgeting and costing; types of ESR; securing international aid; and the livelihood and lifetime of the ESR. Consideration of economic factors also helps to decrease costs and improve the quality of the ESR, in addition to improving its value in the long term.

4. Technical factors include the ease of assembling, disassembling and transporting materials; the size and storage of materials; performance; availability of construction equipment and tools; ease of repairs and maintenance; locations; and services provided to evacuees.

\subsubsection{Stage 3-Sheltering Types}

The sheltering types are a vital productive asset, offering spaces to rest and worship, to care for the elderly and children, and other requirements [42 \& 42]. Selecting the correct types of shelters requires meticulous consideration of every relevant factor [6]. The shelter responses can fall into three categories: short-term, medium-term and long-term. Each requires a particular type of shelter. There is no need to follow every phase; the committee can shift between each phase depending upon the situation.

Short-term emergency shelters which is used mostly in Hajj event, provide lifesaving help and are the simplest type of shelter aid [21]. They involve remaining in other available locations, such as sheltering canters in Almaasam Muzdalifa and Makkah - Jeddah Hwy or parks or gardens or available permanent buildings, including hotels, halls or other usable facilities available for temporary use, for a few hours or up to a few days in emergency situations [4, 5, 6, 29 \& 31]. These types of shelters usually permit the extended preparation of food or extended medical services. Therefore, this type of shelter is suitable for the Hajj context, because they are short-term events. 
The second sheltering type is the medium-term option, which are called t-shelters/houses, and comprise three variations. The first is temporary shelters. These kinds of shelters might also be used in the short-term. A public mass shelter or a simple tent provided for a limited time after a hazard can be considered medium-term shelters [4, 5, and 6]. The International Federation of Red Cross and Red Crescent Societies claims that the length of stay in these shelters might be restricted and, thus, make quick decisions a priority; low budgets should be considered when building these kinds of shelters [21].

\subsubsection{Stage 4-Needs and Ambitions}

This stage begins when natural hazards are predicted. The committee needs to warn those who may be affected. If the area is unsafe, then the committee decides if people must be evacuated to safe areas immediately such as sheltering canters in Almaasam Muzdalifa and Makkah - Jeddah Hwy. Conversely, if a hazard like a flash flood has already occurred, then the committee must evacuate quickly and identify people's ambitions and needs afterwards [22 \& 41]. Subsequently, they must decide what type(s) of shelter to use and estimate the length of time for which it will be used.

\subsubsection{Stage 5-Assessment}

In this phase, the committee assesses initial decisions and decides upon the suitable ESR by reconsidering the priorities in regard to needs, ambitions, staffing and skills, land, materials and their alternative distribution and logistics [21, 22 \& 43].

\subsubsection{Stage 6-Implementation}

The implementation stage is where all actions are set into motion [ $43 \& 5$ ]. Here, the committee should implement final decisions on the suitable ESR that maximise fitness for purpose and improve quality of life and worship for Rahman guests. This stage requires much support regarding labour, training, materials, kits and resources.

\subsubsection{Stage 7-Monitoring}

Monitoring the shelter response after implementation is crucial [22 \& 5]. Both the survivors and the ESR need to be monitored. Additionally, the response must recognise that people who provide the ESR will make extensions, alterations and upgrades to the original plan. Therefore, continuing guidance and monitoring is needed to make sure that such changes do not put the response at risk [21].

\subsubsection{Stage 8- Lessons learned}

All comments and issues during the ESR need to be gathered, discussed and documented in the setting of first stage (meeting of the committee) [22 \& 43]. The benefits are that it can be used to upgrade the guidelines for use in the future to make it more successful for subsequent Hajj events, if needed.

\section{Conclusion}

All pilgrims who affected by natural hazards are entitled to an adequate emergency shelter response. Emergency shelters need to be suitable to reside in, which optimally requires them to be green, sanitary, secure and private places. An emergency shelter needs to protect from wind, rain, heat and cold, among other threats, like disease (such as Covid -19), illness and structural hazards. Every aspect of ensuring such provisions must be addressed and achieved in the ESR guidelines by consideration of essential factors and elements at every stage, which include committee meetings, design factor analysis, shelter types, ambitions and needs, implementation, assessment, monitoring and reflection on lessons learned. In the context of this research, this maintains the ability to offer a rapid, efficient and practical means to shelter displaced Rahman guests. The ESR guidelines must also ensure analysis of particular elements, like economic, technical, environmental, and sociocultural 
factors, to guarantee good value for money and time is saved. Additionally, it helps the stakeholders to decide between the different types of shelter responses that fit the intended purpose. Still, the ESR guidelines need assessment in real-life natural hazard events and also require workshops to teach responsible people how to implement it. Moreover, it requires more participation and co-operation from other sectors to assist in entering the essential information and regularly updating the ESR, as it is a continual procedure that needs regularly scheduled review and revision.

\section{References}

1. Charlesworth, E., Humanitarian Architecture: 15 Stories of Architacts Working After Disaster. 2014, UK: Routledge.

2. Félix, D., J.M. Branco, and A. Feio, Temporary housing after disasters: A state of the art survey. Habitat International, 2013. 40: p. 136-141.

3. Bashawri, A., S. Garrity, and K. Moodley, An Overview of the Design of Disaster Relief Shelters. Procedia Economics and Finance, 2014. 18: p. 924-931.

4. Johnson, C., Impacts of prefabricated temporary housing after disasters: 1999 earthquakes in Turkey. Habitat International, 2007. 31(1): p. 36-52.

5. Johnson, C., G. lizarralde, and C. Gonzalo, A systems view of temporary housing projects in postdisaster reconstruction. Construction Management and Economics, 2006. 24.

6. Johnson, C., Strategic planning for post-disaster temporary housing. Disasters, 2007. 31(4): p. 435458.

7. Ashmore, J., Tents: A guide to the use and logistics of family tents in humanitarian relief, OSHA, Editor. 2004, United Nations.

8. Yoshimitsu, S., et al., Recovery Planning: Transitional Shelter. 2013, International Recovery Platform.

9. Moe, T. and P. Pathranarakul, An integrated approach to natural disaster management: Public project management and its critical success factors. Disaster Prevention and Management, 2006. 15(3): p. $396-413$.

10.T, J., Class notes of the International Short Course in Disaster Risk Reduction and Sustainable Development. 2003.

11.Regnier, P.e.a., From emergency relief to livelihood recovery Lessons learned from post-tsunami experiences in Indonesia and India. Disaster Prevention and Management, 2008. 17(3): p. 410-429.

12.[13] Shaw, R., Indian ocean tsunami and aftermath. Disaster Prevention and Management, 2006. 15(1): p. 5-20.

13.EPC and TCG International, Participatory Planning Guide for Post-Disaster Reconstruction. 2004: India and Washington.

14. Hidayat, B. and C. Egbu, A literature review of the role of project management in post-disaster reconstruction, in C. (Ed) Procs 26th Annual ARCOM Conference. 2010, Association of Researchers in Construction Management: leeds, UK. p. 1269-1278.

15.Amin, S. and M. Goldstein, Data against natural disasters: establishing effective systems for relief, recovery and reconstruction. 2008, World Bank.

16.HM Government, Emergency Response and Recovery 2013, Crown copyright: London.

17.HM Government, Evacuation and shelter guidance, Non-statutory guidance to complement Emergency preparedness and Emergency response and recovery January. 2006.

18.HM Government, Evacuation and shelter guidance, Non-statutory guidance to complement Emergency preparedness and Emergency response and recovery January. 2014.

19.HM Government, DCMS, and ACPO, Humanitarian Assistance in Emergencies. 2006: UK.

20.IRP and ISDR, Guidance Note on Recovery Shelter. 2011, International Recovery Platform Secretariat: Japan.

21.IFRC/RCS, Post-disaster shelter: Ten designs. 2013, International Federation of Red Cross and Red Crescent Societies: Geneva. 
22.IFRC, IFRC shelter kit guidelines. 2010, International Federation of Red Cross and Red Crescent Societies: Switzerland.

23.Corsalis, T. and A. Vitale, Transitional settlement: displaced populations. 2005: Oxfam.

24.Camp Coordination/Camp Management, COLLECTIVE CENTRE GUIDELINES. 2010, United Nations High Commissioner for Refugees and International Organization for Migration.

25.The Sphere Project, Minimum Standards in Shelter, Settlement and NOn-Food Items. 2011.

26.Shelterproject, Transitional Settlement Displaced Populations. 2004, University of Cambridge: UK.

27.Nigel, S., Engineering Project Management, ed. Third. 2007, UK: Wiley-Blackwell.

28.Kats, G. and L. Alevantis, The cost and financial benefits of green buildings- A report to California's sustainable building task force. 2003, Australia.

29.Quarantelli, E.L., PATTERNS OF SHELTERING AND HOUSING IN AMERICAN DISASTERS. University of Delaware, Disaster Research Center, 1991.

30.Wu, J.Y. and M.K. Lindell, Housing reconstruction after two major earthquakes: The 1994 Northridge earthquake in the United States and the 1999 Chi-Chi earthquake in Taiwan. Disasters, 2004. 28(1): p. 63-81.

31.Félix, D., J.M. Branco, and A. Feio. Guidelines to improve sustainability and cultural integration of temporary housing units. 2013. i-Rec conference.

32.Benthall, J. 1993. Disaster, relief and the media, I.B. London, New York: Tauris and Co Ltd. Blaikie, P. et al. 2003. At risk: natural hazards, people's vulnerability and disasters. Second ed. London and New York: Routledge.

33.Ali, A.B. and Ameur, F. 2018. An Assessment of Jeddah's Hydraulic Protection and Management Systems of Flood. Open Access Library Journal. 5(02), p1.

34.Fellows, R. and Liu, A. 2015. Research methods for construction. Oxford: John Wiley \& Sons.

35.Sekaran, U. and Bougie, R. 2016. Research methods for business: a skill-building approach. New York: John Wiley \& Sons.

36.Tan, W. 2004. Practical Research Methods. Singapore: Prentice Hall.

37.Saunders, G. 2011. Family tent, 16m2. IFRC Shelter Research Unit.

38. Robson, C. 2016. Real World Research. Oxford: John Wiley \& Sons.

39.NHHCR. 2014-2018. Global strategy for settlement and shelter. Switzerland: United Nations High Commissioner for Refugees.

40.UNHCR. 2018. Shelter solutions.

41.IFRC and Oxfam GB. 2007. Plastic sheeting, a guidance to specification and use of plastic sheeting in humanitarian relief. International Federation of Red Cross and Red Crescent Societies and Oxfam-GB.

42.United Nations. 2004. Tents: A guide to the use and logistics of family tents in humanitarian relief. Geneva: United Nations.

43.Shelter Centre. 2012. Trasitional Shelter Guidelines. Switzerland: Shelter Centre.

44.El-Anwar, O. et al. 2009. Optimizing large-scale temporary housing arrangements after natural disasters. Journal of Computing in Civil Engineering. 23(2), pp.110-118.

45. Humanitarian Aid and Civil Protection. 2016. DG ECHO Thematic Policy Document: Shelter and Settlements. EU.

46. Massey, N. 2016. The Contract Design Process.

47.Gray, B. and Bayley, S. 2015. Case study: shelter innovation ecosystem. UK: Department for International Development, UK aid Network.

48.General Directorate of Civil Defence. 2020. National Plan for natural disasters risk reduction Ministry of Interior - Saudi Arabia.

49.Tesch, R. 2013. Qualitative research: Analysis types and software. Routledge.

50.Cross, N. and Roy, R. 1989. Engineering design methods. New York: Wiley.

51.General Directorate of Civil Defence. 2018. National Plan for natural disasters risk reduction Ministry of Interior - Saudi Arabia.

52.Ministry of Hajj and Umrah. 2017. The executive plan for the tasks of Hajj and Umrah and its affiliated parties included in the general plan of emergency for Hajj pilgrimage. 
53.Bryman, A. and Bell, E. 2015. Business research methods. USA: Oxford University Press.

54.Davis, J. and Lambert, R. 2002. Engineering in emergencies, a practical guide for relief workers. Second ed. London, United Kingdom: ITDG Publishing.

55.Miles, M.B. and Huberman. 1994. Qualitative data analysis. Thlusand Oaks, California: Sage Publications, Inc. 